\title{
Measuring reaction rates at equilibrium with the isotope doping method
}

\author{
Chen Zhu ${ }^{1, *}$, Yilun Zhang ${ }^{2}$, J Donald Rimstidt ${ }^{1}$, and Honglin Yuan ${ }^{3}$ \\ ${ }^{1}$ Earth and Atmospheric Sciences, Indiana University, Bloomington, IN 47405, USA \\ ${ }^{2}$ Department of Geological Sciences, Virginia Tech, Blacksburg, VA 24061, USA \\ ${ }^{3}$ Northwest University, Department of Geology, State Key Laboratory Continental Dynamic, Xi'an, \\ People's Republic of China, 710069
}

\begin{abstract}
Since the time of J. H. van't Hoff [1], it has been known that chemical equilibrium is dynamic, meaning that at equilibrium, chemical reactions do not cease, but instead the forward and backward reaction rates are equal. The constant concentrations at equilibrium preclude the use of concentrations to measure reaction rates at equilibrium. Therefore, with the exception of a few special cases, no reaction rates at equilibrium have been published in the literature of chemistry, physics, or chemical engineering. Here we report dissolution and precipitation rates at equilibrium for quartz and barite with the isotope-doping method. Experimental data show that dissolution and precipitation rates are equal at equilibrium, indicating the principle of detailed balance (PDB) appear to be applicable at these experimental conditions. The PDB has been a cornerstone for irreversible thermodynamics and chemical kinetics for a long time, and its wide application in geochemistry has mostly been implicit and without experimental testing of its applicability. Nevertheless, many extrapolations based on PDB without experimental validation have far reaching impacts on society's mega environmental enterprises. The isotope doping method appears to able to test its applicability for a variety of minerals at a wide range of conditions.
\end{abstract}

\section{Introduction}

The isotope doping technique introduces an enriched rare isotope of an element to an experimental solution that is interacting with a mineral or a suite of minerals that have normal or natural isotopic compositions [2]. The technique has been used in the past with various isotopes. For example, Zuddas et al. [3] and Seimbille et al. [4] used ${ }^{39} \mathrm{~K}$ and ${ }^{84} \mathrm{Sr}$ to simultaneously measure dissolution rates of K-feldspar, biotite, and plagioclase during the hydrothermal alteration of a granite; Beck et al. [5] used Ca isotopes to study the reaction kinetics of calcite recrystallization at elevated temperature; and Curti et al. [6] used radioactive barium isotopes to study isotope-exchange in barite. Gruber et al. [7] measured albite dissolution rates with $\mathrm{Si}$ isotopes.

\footnotetext{
*Corresponding author: chenzhu@indiana.edu
} 


\section{Experimental method}

The silicon in quartz has three stable isotopes and the natural quartz used in our experiments has an isotopic composition of $92.23 \%{ }^{28} \mathrm{Si}$, $4.67 \%{ }^{29} \mathrm{Si}$, and $3.10 \%{ }^{30} \mathrm{Si}$. In our equilibrium experiments a solution initially containing nearly $99.99 \%{ }^{29} \mathrm{Si}$ was maintained at or near equilibrium with quartz and sampled periodically to find the ${ }^{28} \mathrm{Si}$ and ${ }^{29} \mathrm{Si}$ concentrations. We used the initial rate method [8] to find the rate of appearance of ${ }^{28} \mathrm{Si}$ in solution, which gives the dissolution rate at equilibrium, and the rate of disappearance of ${ }^{29} \mathrm{Si}$, which gives the precipitation rate at equilibrium. The $\mathrm{Si}$ isotope abundances in the experimental solutions evolved significantly over the course of experiments but the initial rate method determined the rate at time zero thereby avoiding complications associated with minor but measurable isotopic fractionation.

The dissolution experiments were batch reactor experiments conducted at $50 \pm 1{ }^{\circ} \mathrm{C}$. The starting solution for the experiments contained $340 \mu \mathrm{M}{ }^{29} \mathrm{SiO}_{2}$, which is the solubility of quartz at $50{ }^{\circ} \mathrm{C}$ [9], and the solution was reacted with an ion exchange resin to remove cations that would catalyze the quartz dissolution rate. These solutions remained within $\pm 0.3 \mathrm{~kJ} / \mathrm{mol}$ of equilibrium throughout the experiments. The $\mathrm{pH}$ of the starting solutions was near 5.5 for both types of experiment. More detailed analytical methods are described in [10].

For barite experiments, natural barite crystals were used in isotope exchange experiments in aqueous solutions that were in bulk chemical equilibrium with barite. The aqueous solutions had $\sim 54.556 \%{ }^{137} \mathrm{Ba}$ and $37.910 \%{ }^{137} \mathrm{Ba}$, which were significantly different from the isotope composition of barite crystals that have a natural abundance of $11.232 \%{ }^{137} \mathrm{Ba}$ and $71.699 \%{ }^{138} \mathrm{Ba}$.

\section{Results}

Figure 1 shows the fractions of $\mathrm{Si}$ isotopes versus time for the equilibrium experiments. The dissolution and precipitation rates are essentially the same, thus demonstrating that we have measured the dissolution rate constant at equilibrium. One application of our experimental results is the validation of equilibrium constants for quartz solubility. Rimstidt [9] measured quartz solubility at $25,50,75$, and $96^{\circ} \mathrm{C}$ in experiments up to 4917 days. These long-term experimental data formed the basis for establishing quartz solubility as a function of temperature, and also for deriving the standard thermodynamic properties for the aqueous species $\mathrm{H}_{4} \mathrm{SiO}_{4}(\mathrm{aq})$ [9,11]. However, all experiments approached the quartz solubility from undersaturation and the reverse experiments - precipitation from oversaturation is far more complicated experimentally. Applying the principle of detailed balance,

$$
K=+/ k
$$

it was observed that the $\log K$ value for reaction (3) at $50{ }^{\circ} \mathrm{C}$ in pure water is -3.50 , which is within the experimental uncertainties of [9]. In Equation (1), $K$ is the equilibrium constant, $k+$ and $k$ - denote rate constants for forward and backward reactions, respectively. 


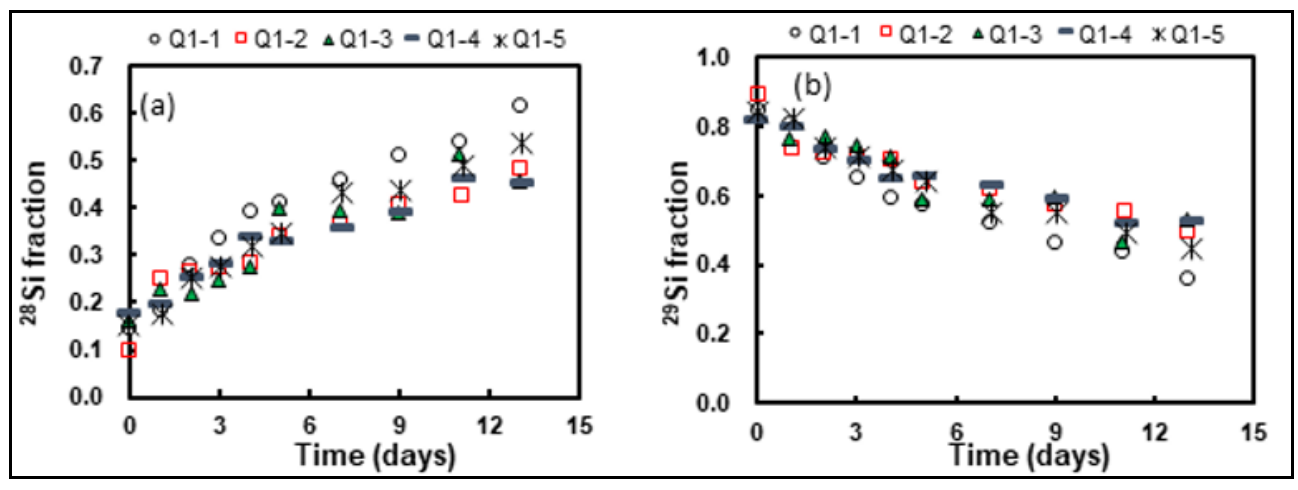

Fig. 1. Plots of Si isotope fractions in experimental solutions over time: (a) ${ }^{28} \mathrm{Si}$ fraction; (b) ${ }^{29} \mathrm{Si}$ fraction. The solution was saturated with quartz and doped with $99.99 \%{ }^{29} \mathrm{Si}$. The first sample was taken after 15 minutes. The increase of ${ }^{28} \mathrm{Si}$ concentration (fraction times dissolved elemental $\mathrm{Si}$ concentration) is due to the dissolution of quartz while the decrease of ${ }^{29} \mathrm{Si}$ concentration is due to the precipitation of quartz.

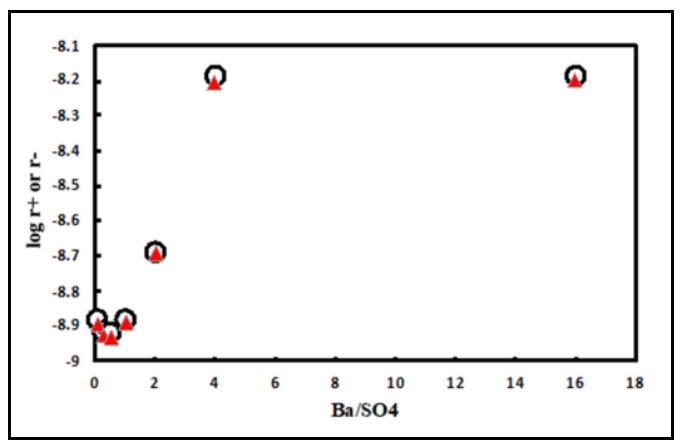

Fig. 2. Rates from barium isotope exchange experiment at $22^{\circ} \mathrm{C}$ and $\mathrm{pH} 5.5$. The barium and sulfate concentrations are constant over time and at equilibrium concentrations.

Figure 2 shows the dissolution and precipitation rates for barite. The Ba exchange reaction will cause the ${ }^{137} \mathrm{Ba}$ concentration in the solutions to increase and the ${ }^{138} \mathrm{Ba}$ concentration to decrease over time (Fig. 2 above) through the reaction:

$$
{ }^{137} \mathrm{Ba}^{2+}+{ }^{138} \mathrm{BaSO}_{4 \text { (barite) }}={ }^{138} \mathrm{Ba}^{2+}+{ }^{137} \mathrm{BaSO}_{4 \text { (barite) }}
$$

The $\mathrm{Ba}^{2+}$ release and uptake rates can be calculated from the rate of change of the ${ }^{138} \mathrm{Ba} /{ }^{137} \mathrm{Ba}$ ratios in the solutions at various sampling times. Unlike the rates reported in previous literature, these rates are unidirectional rates, not net rates.

For equal values between dissolution and precipitation rates indicate that the Principle of Detailed Balance is applicable for barite under these experimental conditions. The variation of barite dissolution and precipitation rates as a function of barium and sulfate concentration ratios in the experimental solution may indicate that barium hydration/dehydration as the limiting step for barite dissolution and precipitation.

\section{Concluding remarks}

To summarize our findings, we have demonstrated that:

(a) The isotopic contrast, precision, and sensitivity of isotope analysis allow detection of the dissolution of a minuscule amount of silicate minerals in aqueous solution, orders- 
of-magnitude more sensitive than the traditional method. Therefore, the $\mathrm{Si}$ isotope doping method makes it possible to measure rates at ambient temperature, circumneutral $\mathrm{pH}$, and near-equilibrium conditions.

(b) $\mathrm{Si}$ isotope fractionation during albite dissolution ranged from ${ }^{30} \varepsilon_{\text {sol-ab }}$ of -2.870 to $0.804 \%$, significant for Si biogeochemical cycling, but resulting in $< \pm 0.04 \%$ errors in rate determination. The fractionation factors in silicate dissolution and precipitation reactions are in the range of 2-4\% [13], which will introduce negligible errors for this purpose.

(c) The precipitation of Si consumes silica but results in only slight changes of Si isotope ratios in experimental solutions, which makes the isotope doping method applicable when Si-precipitation occurs either as the backward reaction or as secondary phase precipitation.

In theory, the isotope doping method can be applied to many solids to test the range of validity of the near equilibrium rate constants. MC-ICP-MS technology eases the analytical problems associated with using this experimental design for a wide range of non-silicate minerals and solids using the increasing number of non-traditional stable isotopes (such as $\mathrm{Mg}, \mathrm{Fe}, \mathrm{Li}$ ). Therefore, the application of this method is not limited to geochemistry, but can be used in chemistry, chemical engineering, and environmental sciences as well.

All experiments were carried at Indiana University, USA with the exception of $\mathrm{Si}$ isotope analysis which was carried out at State Key Laboratory of Continental Dynamics at Northwest University in China. Financial support of this research was provided by the U.S. NSF grant EAR-1225733 to CZ.

\section{References}

1. J.H. van't Hoff, Etudes de dynamique chimique, Fredrick Muller, Amsterdam (1884)

2. J. Gaillardet, in: S.L. Brantley, J.D. Kubicki, A.F. White (Eds.), Kinetics of WaterRock Interaction, Springer, New York (2008)

3. P. Zuddas, et al., Chem Geol, 121, 145-154 (1995)

4. F. Seimbille, et al., Earth Planet Sci Lett, 157, 183-191 (1998)

5. J.W. Beck, et al., Chem Geol, 97, 125-144 (1992)

6. E. Curti, et al., Geochim. Cosmochim. Acta. 74, 3553-3570 (2010)

7. C. Gruber, L. et al., Geochim. Cosmochim. Acta. 104, 261-280 (2013)

8. J.D. Rimstidt, Geochemical rate models: An introduction to geochemical kinetics, Cambridge University Press, Cambridge (2013)

9. J.D. Rimstidt, Geochim Cosmochim Acta 61, 2553-2558 (1997)

10. C. Zhu, et al., Chem. Geol. 445, 146-163 (2016)

A. Stefansson, Chem. Geol. 172, 225-250 (2001)

11. Z. Liu, et al., Geochem Perspect Lett 2, 78-86 (2016)

12. S. Opfergelt, P., Delmelle, C. R., Geosci. 344, 723-738 (2012) 